\title{
Validation of the Suitability of Stripped Lipid as a Skin Model in Plasma Medical Investigations
}

\author{
Joanna Hirschberg1,2, Christoph Gerhard1,2, Andrea Braun'3 , Stefan Grottker1, \\ Alexander Krupp ${ }^{2}$, Steffen Emmert ${ }^{3}$, Wolfgang Viöl1,2 \\ ${ }^{1}$ Department of Sciences and Technology, HAWK University of Applied Sciences and Arts, Göttingen, Germany \\ ${ }^{2}$ Fraunhofer Institute for Surface Engineering and Thin Films IST, Application Center for Plasma and Photonic \\ APP, Göttingen, Germany \\ ${ }^{3}$ Department of Dermatology, Venerology and Allergology, University Medical Center Göttingen, Göttingen, \\ Germany \\ Email: wolfgang.vioel@hawk-hhg.de
}

Received 21 January 2015; accepted 2 February 2015; published 12 February 2015

Copyright (C) 2015 by authors and Scientific Research Publishing Inc.

This work is licensed under the Creative Commons Attribution International License (CC BY).

http://creativecommons.org/licenses/by/4.0/

(c) (i) Open Access

\section{Abstract}

In this work, the suitability of lipid stripping as an alternative model of stratum corneum for plasma medical studies was investigated. Plasma treatment experiments were performed on samples prepared by the cyanoacrylat stripping method. Therefore, two different dielectric barrier discharge-based plasma sources driven by high-voltage pulses in the microsecond and nanosecond range were applied. The lipid sample heating, change in $\mathrm{pH}$-value, and the interaction with plasma-induced UV-radiation are presented and discussed with respect to existing findings on skin samples. After the plasma treatment, the lipid stripping shows similar changes compared to human skin relating to sample heating and $\mathrm{pH}$-value. The investigation of the interplay with UVradiation shows a high absorption in the wavelength range of $250 \mathrm{~nm}$ up to $400 \mathrm{~nm}$. Further, the thickness, surface structure, and composition of lipid stripping samples were determined. The stripped sample shows a thickness of $3 \pm 1 \mu \mathrm{m}$ whereby approximately $30 \%$ of the sample surface is covered by lipids. In addition, it was shown that there are no changes in structure caused by the sample preparation. Based on the results of this work, it can be stated that lipid stripping represents an appropriate skin model for plasma medical investigations.

\section{Keywords}

Lipid Stripping, Skin Model, Plasma Medicine, Dielectric Barrier Discharge 


\section{Introduction}

Applications of non-thermal plasma (ionized gas) in the medicine have been examined during the last years and have become an increasingly important topic. In this context the challenge is the treatment of living, heat-sensitive objects such as human skin, chronic wounds, or microorganisms. The most commonly used plasma discharge type is the dielectric barrier discharge (DBD), which is a "cold", non-equilibrium plasma, supported by electric fields. Biologically active components, which are produced inside the discharge volume, are UV-radiation, heating, electrical current and fields, reactive species as well as hot electrons [1]-[3]. The energy transfer from hot electrons is less effective than cooling of reactive species and uncharged gas particles, resulting in a low gas temperature and negligible sample heating [4]-[7].

In several biological studies and clinical trials, interactions and effects during and after plasma treatment, are examined. The sterilisation and stimulation of tissue and surfaces is one main research topic [6] [8]. The inactivation of microorganisms without damaging healthy cell lines was reported in various publications. In growth studies with bacteria, yeasts, and fungi, "cold" plasma was used as microbicidal tool [4] [5] [9]. Membrane damage provoked by reactive oxygen species and DNA degradation were identified as possible modes of action [10]. Further utilisations of plasma in medicine are dental treatments for removing caries bacteria [11] or blood coagulation caused by direct contact with non-thermal plasma, which triggers selective natural mechanisms [8] [12] [13]. Furthermore, the whole blood viscosity could be influenced by plasma [13]. In addition, cancer therapy was referred to as a possible application for plasma medicine. Fridman et al. showed an inactivation of cancer cell lines inducing apoptosis during therapeutic treatment [14]. An alternative plasma-based treatment against blood disease leukaemia was examined in other studies [15].

An increasing number of patients with atopic dermatitis, ichthyosis, or psoriasis generate the necessity of effective, painless, and economic therapeutic options. Plasma medicine offers a lot of possibilities in treatment of skin diseases, but interactions between discharge and human skin were not acceptably understood for a largescale use. By using non-thermal plasma on human skin, different effects were observed. Reactive nitrogen species, generated in the course of a plasma treatment procedure, give rise to a significant acidification of skin [16]. Also, changes in lipid composition were investigated, using X-Ray Photoelectron Spectroscopy for analysing lipid stoichiometry [17]. In these and similar studies, different suitable models for human skin were used such as representative mice models or pig ear skin [8] [18] [19]. An alternative to these models is the lipid stripping method in which stratum corneum of human skin is collected in a non-invasive process. No statistically significant differences in composition between such samples and mechanically removed samples were determined [20].

In this work, the suitability of lipid stripping samples as models for human skin in plasma application was investigated. The most important advantage of this method arises from the possibility to investigate diseased skin samples regarding its lipid composition and plasma-induced changes without the need for a clinical trial. To ensure that the resulting plasma effects on lipid strippings are comparable to those observed on human skin and therefore the changes studied in stoichiometry are representative, the lipid interaction with biologically relevant plasma components is examined. Compared to previous studies, the necessary requirements for a skin model in plasma medical applications, sufficiently high proportion of water, absorption of UV-radiation and similar heat conduction were investigated here. The UV-absorption was considered directly; in case of heat conduction, the resulting sample heating was observed. To examine the water content, the nitric and nitrous acids formed by moisture and reactive nitrogen species were considered. In addition, the structure, composition, and size of the lipid layers were taken into account.

\section{Materials and Methods}

\subsection{Collection of Stratum Corneum by Cyanoacrylate Stripping}

The stratum corneum (SC) consists of cornified cells (corneocytes) embedded in a lipid matrix. The lipid sample preparation was realized by removing a part of SC from the forearm of healthy volunteers. This procedure corresponds to a well-established method for collecting SC and is described in detail in [20]. Therefore, one drop of cyanoacrylate adhesive LiquiBand ${ }^{\circledR}$ (MedLogic Global Limited, Plymouth, United Kingdom) was deposited on an aluminium plate that was pressed tightly onto the skin and stripped of after 60 seconds. The applied surface pressure provoked a spreading of adhesive resulting in a sample size of approximately $2 \times 2$ square centimeters. 
For a comparable initial situation, the particular tapping point was cleaned up with acetone before sample collection. In addition, the contact with water and soap was avoided for 12 and 24 hours, respectively, before sample collection.

\subsection{Dielectric Barrier Discharge}

In this study, we used two DBD sources, consisting of the same electrode geometry but different power supplies. The plasma sources comprised a ring-shaped copper electrode with a diameter of 8 millimeters covered by a ceramic $\left(\mathrm{Al}_{2} \mathrm{O}_{3}\right)$ cylinder with a wall thickness of one millimeter. The grounded opposite electrode consisted of stratum corneum lipid layers placed on an aluminium plate. The inter-electrode spacing was kept constant at a value of one millimeter (see Figure 1), the samples are treated for 60 seconds. In both discharges, ambient air was used as working gas. Using this arrangement gives rise to a certain restriction: During plasma treatment of human skin, the top of SC layer is exposed, whereas only an inner layer of SC can be treated when using stripped lipids. Against this background, the composition of this inner layer was studied by Marschewski et al. in [17]. Here, a good agreement to the composition of human skin, i.e. the above-mentioned top SC layer, was shown there.

The DBD was first driven by a pulsed high-voltage power supply with pulse durations in the $\mu$ s-range. In a second setup, pulse durations in the ns-range were applied. The particularly resulting plasma parameters are shown in Table 1 . The methods used to characterize the discharges were described in detail in [21]. The variation of pulse duration is of specific interest since this value strongly influences the resulting plasma parameters. Several effects, for example a more efficient formation of reactive species such as $\mathrm{O}_{3}$ or $\mathrm{NO}_{\mathrm{X}}$, a more homogeneous appearance of discharge, or more effective antimicrobial properties, can be observed in discharges with pulse durations in the ns-range [21]-[23]. Both discharge modes are currently used in plasma medical studies, so that the impact of pulse durations on the resulting plasma parameters are to be investigated on stripped lipid layers.

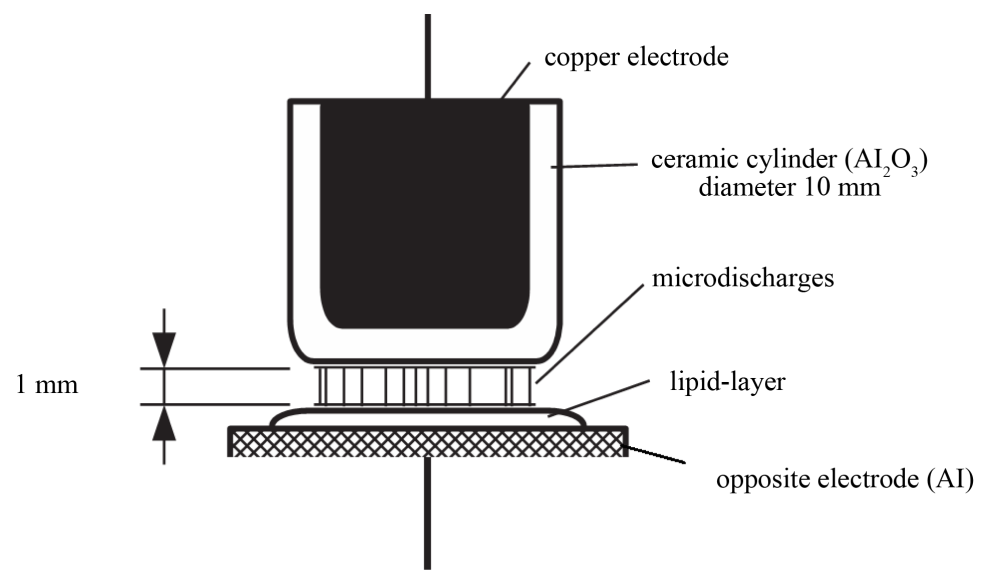

Figure 1. Schematic structure of electrodes [21].

\begin{tabular}{ccc} 
Table 1. Plasma parameters [21]. & \\
\hline & $\mu$ s-source & ns-source \\
\hline Peak voltage & $7.5 \mathrm{kV}$ & $11.7 \mathrm{kV}$ \\
Pulse duration & $70 \mu \mathrm{s}$ & $600 \mathrm{~ns}$ \\
Pulse repetition rate & $300 \mathrm{~Hz}$ & $300 \mathrm{~Hz}$ \\
Dissipated power & $200 \mathrm{~mW}$ & $700 \mathrm{~mW}$ \\
Rotational temperature = gas temperature & $375 \mathrm{~K}$ & $330 \mathrm{~K}$ \\
Mean electron energy & $(10.7-11) \mathrm{eV}$ & $8.25 \mathrm{eV}$
\end{tabular}




\subsection{Thermographic Studies}

A well-known effect of direct treatment with "cold" plasma is a slight sample heating up to a few degrees above room temperature [6] [7]. This heating depends on the used plasma device, the processing time as well as the heat capacity and thermal conductivity of the samples. Against this background, thermographic studies of the heating of stripping samples were compared to the heating of skin. For contactless temperature measurements, an IR camera VarioCAM ${ }^{\circledR}$ high resolution (InfraTec GmbH, Dresden, Germany) was used. Infrared radiation in the range of $7.5 \mu \mathrm{m}$ up to $14 \mu \mathrm{m}$ was detected in order to obtain spatial temperature information. Investigations of chronological sequences were realized by taking image series with repetition rates of one shot per second.

\subsection{Analysis of pH-Value}

It has already been shown that direct plasma treatment of skin with ambient air as working gas has an acidifying effect which lasts for several hours. This is due to the formation of $\mathrm{NO}_{\mathrm{x}}$ during plasma treatment and a subsequent reaction of $\mathrm{NO}_{\mathrm{X}}$ to nitric and/or nitrous acid with the existing water in the sample [16]. For the measurements, a pH-probe SkinpH-Meter ${ }^{\circledR}$ (Derma Unit SSC 3, Courage + Khazaka electronic GmbH, Cologne, Germany) was used. This probe consists of a glass electrode with integrated calomel reference electrode and detects the potential-difference which depends on the $\mathrm{pH}$-value of the measuring solution. In this work, a defined amount of distilled water $(25 \mu \mathrm{L})$ was applied to samples and measurements were taken immediately after and in discrete time intervals after plasma treatment. For each data point, six lipid samples were used.

\subsection{Optical Setup}

Generally, UV-radiation has been identified as a biologically active component in plasma medicine [24] [25]. In the course of the plasma treatment procedure the radiation interacts with the top layers of skin. In this work, the transmission and absorption properties of the samples were examined by the preparation of lipid stripping specimen on UV-transparent fused quartz. The transmission of the cyanoacrylate adhesive and the lipid stripping were studied in a range of 200 to $400 \mathrm{~nm}$. For this purpose, a UV-VIS spectrometer (Lambda 650, PerkinElmer Inc., Massachusetts, USA) was used.

\subsection{Dermatologically Studies}

In order to provide statements about the thickness of lipid stripping samples, coloured histological sections were prepared. The samples were cut with a thickness of $5 \mu \mathrm{m}$ by a cryostat (CM $3050 \mathrm{~S}$, Leica Microsystems Nussloch GmbH, Nussloch, Germany): A formulation of water-soluble glycols and resins (Tissue-Tek ${ }^{\circledR}$ O.C.T: Compount, Sakura Finetek Germany GmbH, Staufen, Germany) was used for the embedding of samples. For staining, the fluorescent and lipophilic dye Nile Red (Diethylamino-benzophenoxazinon) was used which attaches to lipid constituents of the sample. Furthermore, a fluorescent staining was applied, the so-called Dapi dye (Diamidin-phenylindol). This dye caused a visibility of cell nuclei by the attachment to DNA, whereby deeper dermal layers were defined. For characterization of the frozen sections, a fluorescence microscope (Axio Imager M1, Carl Zeiss AG, Oberkochen, Germany) was used. By comparing histological sections with or without previously removed lipid stripping, the ablated portion of the stratum corneum - and thus the thickness of the samples - can be determined. It has already been shown that the composition of lipid stripping samples has no significant differences to mechanically removed samples [20]. Here the composition of the surface of stripping samples was examined. For this purpose the lipid stripping were again prepared with the lipophilic dye Nil Red and evaluated by fluorescence microscopy. The proportion of the intercellular lipid on the sample surface was determined by estimating the coloured areas using a Matlab routine. In order to examine the surface structure of the lipid samples a scanning electron microscope (SEM) (JSM_5600 LV, JOEL GmbH, Eching, Germany) was used, which was also applied for characterization of mechanically removed samples [26]. By plating the non-conductive samples with a gold coating charging effects were prevented and therefore the image quality was increased.

\section{Results and Discussion}

\subsection{Sample Heating}

The lipid stripping samples were treated for 60 seconds, where the discharge gap was one millimeter. During 
plasma treatment interactions of the heavy gas particles (ions and neutral particles) induce a certain temperature rise. After treatment, the temperature of the sample treated by $\mu$ s-plasma was about $297.6 \mathrm{~K}$. Using ns-plasma, the sample temperature was $299 \mathrm{~K}$. In relation to room temperature of $293.2 \mathrm{~K}$ this corresponds to a marginal sample heating of $4.4 \mathrm{~K}$ in the case of $\mu$ s-plasma treatment and $5.8 \mathrm{~K}$ for ns-plasma treatment (see Figure 2). These temperature values were averaged over a circular area with a diameter of $8 \mathrm{~mm}$ and can be specified with an accuracy of $0.5 \mathrm{~K}$. The measured electrode temperatures were above the sample temperatures, i.e. $299.9 \mathrm{~K}$ in the case of $\mu$ s-plasma and about $301.3 \mathrm{~K}$ in the case of ns-plasma.

The comparatively increased heating caused by ns-plasma corresponds to our expectations and can be explained by the much higher dissipated power (factor 3.5). The lower gas temperature of the ns-source is not in contradiction of this result. In determining this temperature, the hot filaments of the discharge have a major impact based on their high light emission. These filaments occur especially in $\mu$ s-plasma, the ns-plasma shows a more homogeneous appearance, resulting in the lower gas temperature. However, due to the formation of filaments within the discharge locally higher temperatures on the sample surface cannot be excluded. After a time interval of $25 \mathrm{~s} / 35 \mathrm{~s}$ ( $\mu$ s-plasma/ns-plasma), the initial temperature of the investigated lipid stripping samples is re-constituted.

The observed heating is directly related to the thermal conductivity and heat capacity of the lipid samples. In a similar study performed on human skin an increase in temperature of $3.5 \mathrm{~K}$ on the sample surface after one minute plasma treatment was reported [6]. This result is in good agreement with our observations, so it is possible to proceed from a comparable heating of both skin and lipid-stripping samples. Furthermore, these results show that the thermal conductivity and heat capacity of the lipid samples cause no adverse influence. This issue was investigated since in the course of excessive heating, the thermal impact causes destruction and degeneration processes in cells as well as structural alterations in proteins [25].

\subsection{Acidifying Effect}

Both applied plasma sources cause a significant change in $\mathrm{pH}$-value on the lipid stripping surface after one minute of plasma treatment. In Figure 3 the temporal development of $\mathrm{pH}$-value for $\mu \mathrm{s}-$ and ns-plasma is shown. Immediately after plasma treatment the changes in $\mathrm{pH}$-value are about $\Delta \mathrm{pH}=1.7$ for $\mu$ s-plasma and about $\Delta \mathrm{pH}=$ 2.2 for ns-plasma. The stronger acidifying effect in the case of applying the ns-source meets our expectations because we assume a higher concentration of $\mathrm{NO}_{\mathrm{X}}$ species in the discharge volume. This assumption was based on the increased dissipated power as well as higher discharge currents of ns-plasma.

Comparing the acidifying effects on lipid-stripping samples and human skin, the initial pH-value, the changes directly after plasma treatment and the $\mathrm{pH}$-value 30 minutes after plasma treatment were examined. The initial value as well as the $\mathrm{pH}$-value observed immediately after one minute of plasma treatment show a good agreement (see Figure 4). It can thus be assumed that the adhesive used for stripping sample preparation has no influence on the lipid layers. Furthermore, the water content of the stripped lipids is high enough for the formation of nitric and nitrous acid on the sample surface, so the stripping samples represent well the human skin with

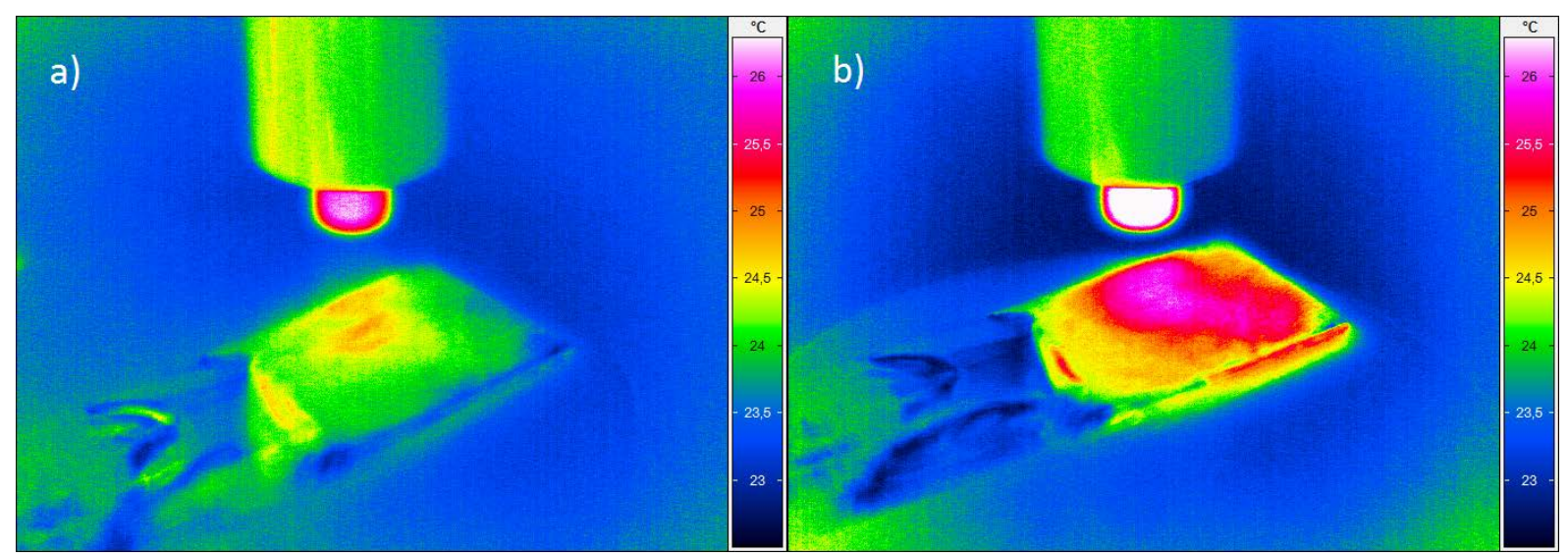

Figure 2. IR-picture of lipid samples after one minute of plasma treatment. (a) $\mu$ s-plasma source; (b) ns-plasma source. For a better comparability the same temperature scale was used. 

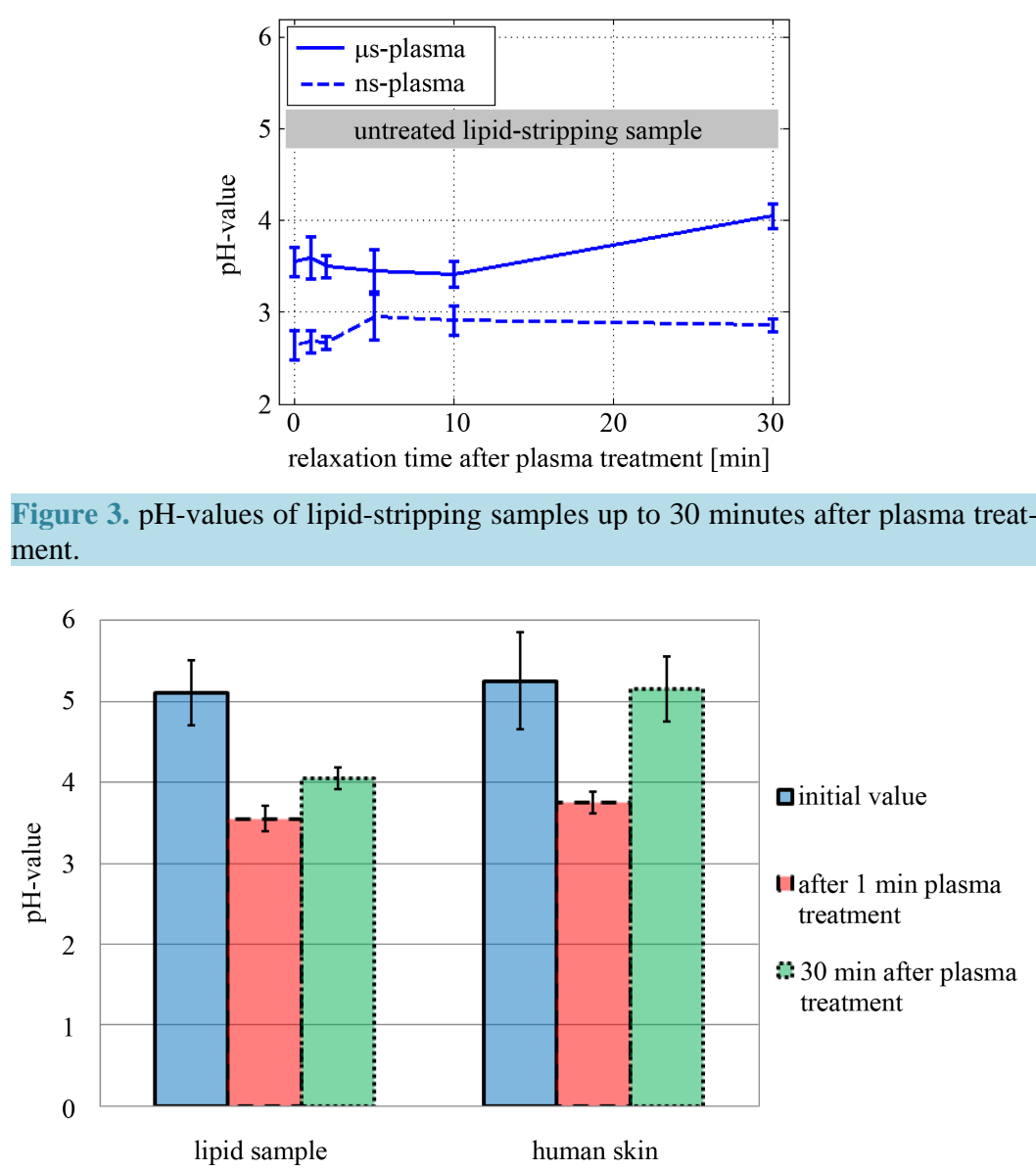

Figure 4. pH-value before, immediately after, as well as 30 minutes after plasma treatment; lipid-stripping sample treated with $\mu$ s-plasma, human skin treated with a similar $\mu$ s-plasma [28].

respect to the resulting $\mathrm{pH}$-value. However, relating to the time course of $\mathrm{pH}$-value, Figure 4 shows a faster approximation to the initial value on human skin. This fact could be explained by the so-called skin-breathing, which describes the admission of atmospheric oxygen in human epidermis and dermis [27]. Based on the time dependency of the acidifying effect, lipid-stripping samples cannot fully represent the characteristics of human skin.

\subsection{UV-Radiation}

In Figure 5 the absorption of lipid-stripping samples in the UV-region as well as the plasma emission intensity are presented. It should be noted that the absorption was measured for the layer system fused quartz, cyanoacrylate adhesive, and stratum corneum. Such measurement was performed since there are several considerable effects of UV-irradiation on lipids: fragmentation of carbon chains, hydrogenation within double bonds of unsaturated compounds as well as the creation of oxygenated groups from unsaturated lipids [24]. These reactions provoke changes in lipid composition and thus represent a part of the expected plasma-induced modifications. The absorption behavior of the lipid-stripping samples shows a good agreement with studies on human skin [29]. Consequently, the lipid-stripping sample can be used as a model of stratum corneum regarding UV-radiation, which represents a biologically active component.

\subsection{Dermatological Studies}

The reference point for determining the thickness of lipid-stripping samples is the coloured profile illustrated in Figure 6. Here, the stratum corneum with its individual layers and the subjacent epidermis are displayed. By 


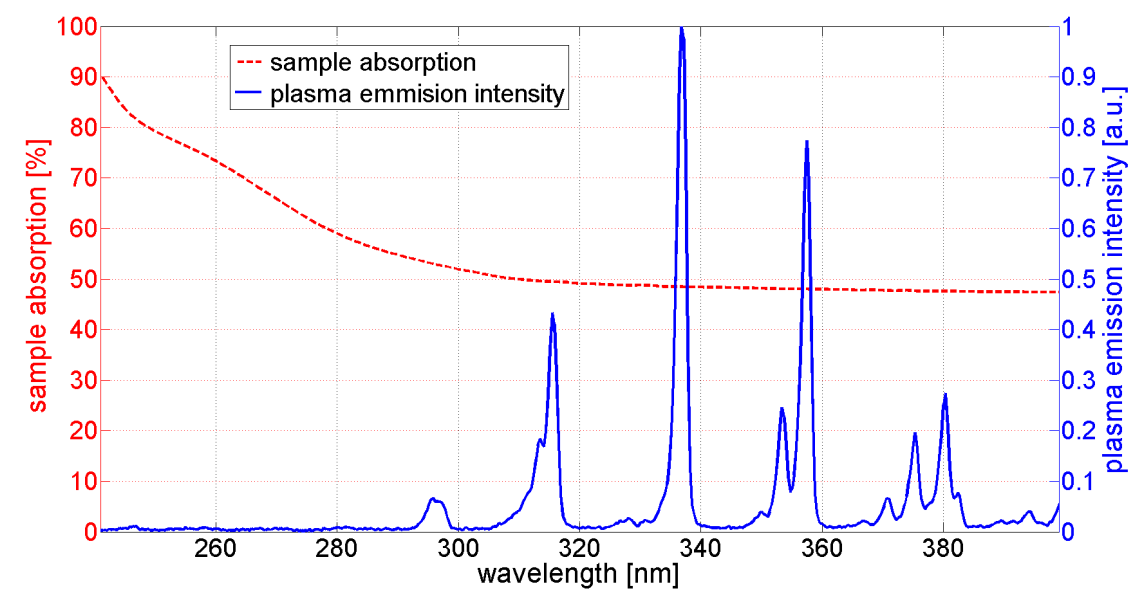

Figure 5. Sample absorption of UV-radiation and emission spectra of $\mu$ s-plasma source.

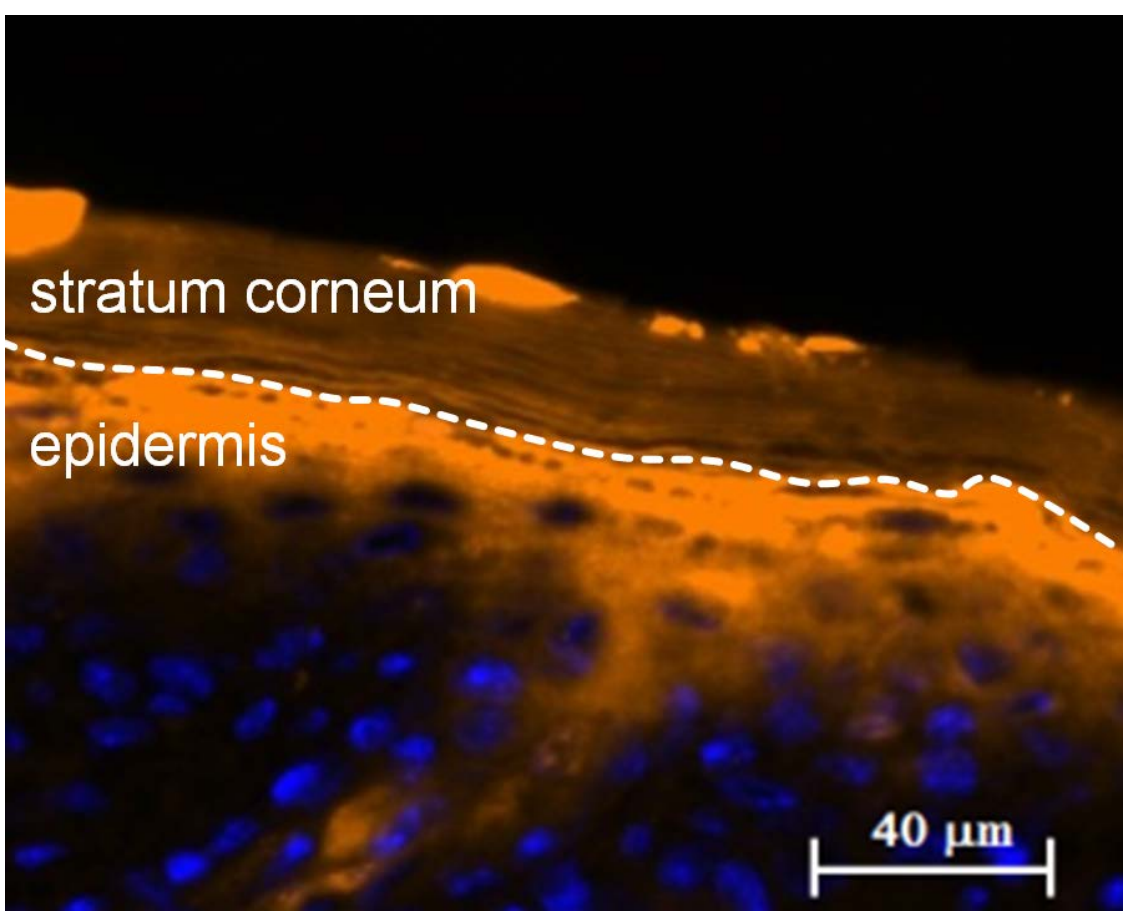

Figure 6. Histological section of human skin coloured with Nile Red and Dapi dye.

comparing histological sections with or without previously removed lipid stripping, the thickness of the stripping samples was determined to amount to $3 \pm 1 \mu \mathrm{m}$. The determination is based on five samples; in each case three points of measurement were evaluated, the used magnification is about 20 -fold. Given this measured thickness it is possible to perform depth-resolved characterization by stripping several series successively. These studies are of particular interest in plasma medicine since in this way, the penetration depth of a plasma treatment in skin could be validated on the basis of various parameters. The proportion of intercellular lipids covering the surface of stripping samples was determined by evaluating the coloured areas after staining with Nile Red. Staining intensity was considered for analyses. Approximately 30\% of the surface was covered with lipids with a fluctuation of $\pm 5 \%$. In Figure 7, a stained lipid-stripping is shown. The black areas represent the corneocytes whereas the bright areas in between show the lipid matrix in which the corneocytes are embedded.

During a direct plasma treatment of stripping samples, the plasma components interact with the intercellular lipid matrix. The dead cornified cells (corneocytes) remain nearly unaffected. Therefore, the ratio of lipids on the sample surface could be used to evaluate changes in lipid matrix qualitatively, since now the signal generat- 
ing area could be estimated.

For investigating the surface structure of stripping samples a SEM was used. The applied imaging method was the secondary electron contrast. In Figure 8(a) an overview image is shown, where the characteristic network structure of skin can be seen clearly. In Figure 8(b) a detailed image is presented, showing individual corneocytes. The represented structure corresponds well with the findings in other studies, where mechanically removed samples were examined [26]. It can thus be assumed that there is no change in structure caused by the sample preparation procedure, i.e. stripping. The stripping samples are thus able to represent the structure of the stratum corneum.

\section{Conclusion}

The presented findings on $\mu s-$ and ns-plasma treatment of lipid stripping samples reveal the suitability of such specimen as a model of SC lipid for plasma medical investigations. In terms of sample heating, a plasma-induced increase in temperature by $4.45 \mathrm{~K}(\mu \mathrm{s})$ and $5.85 \mathrm{~K}(\mathrm{~ns})$, respectively, was determined. The heating is of the same order of magnitude as reported in the case of plasma treatment of skin, i.e. $3.5 \mathrm{~K}$. In addition, the investigated samples feature a similar acidification behavior as skin as shown by the comparison of the particular $\mathrm{pH}$-values for $\mu$ s-plasma treatment. However, the lipid stripping samples show different $\mathrm{pH}$-value relaxation from skin and are thus not applicable for time-resolved investigations. It is shown that similar to stratum corneum, lipid stripping samples have sufficient UVA and UVB absorption, resulting in the coupling of UV-irra-

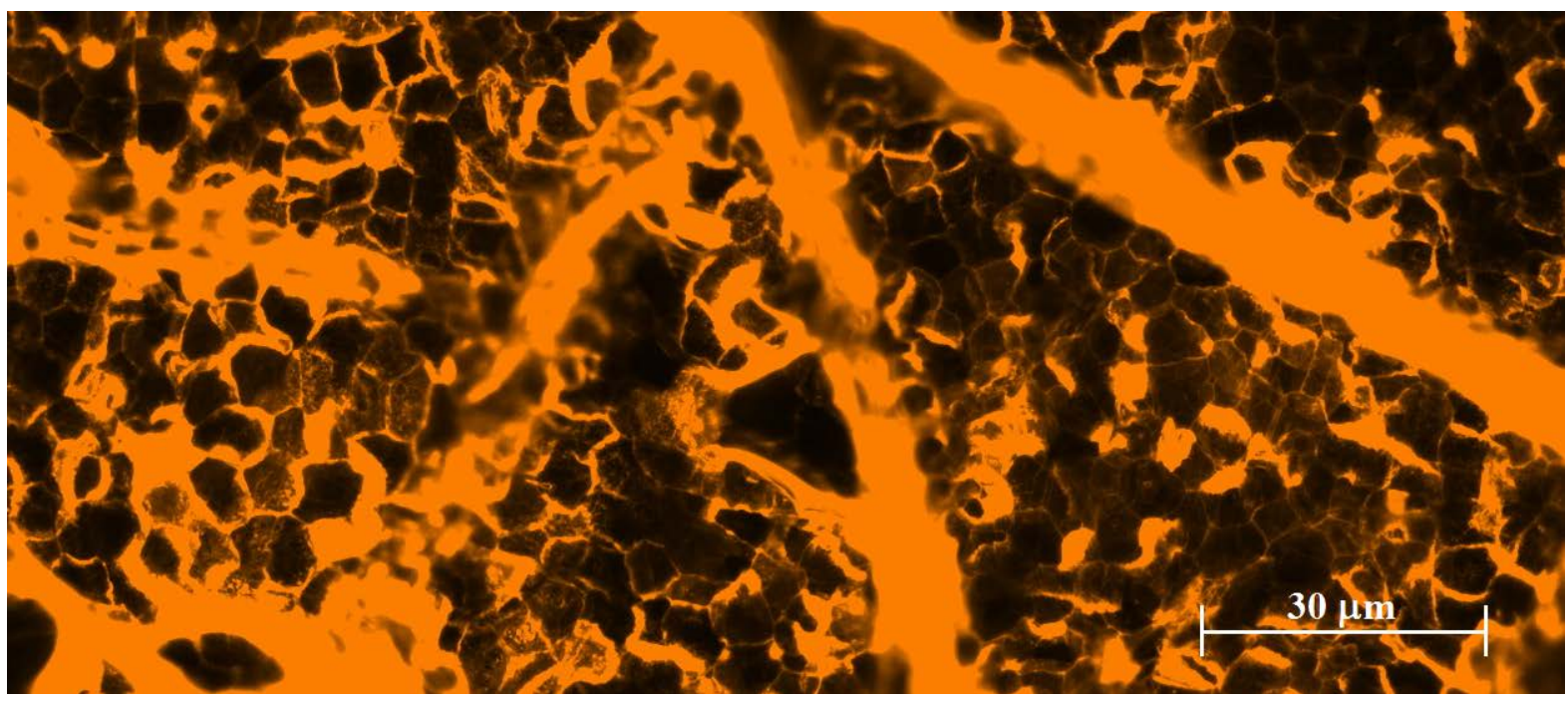

Figure 7. Lipid-stripping sample stained with Nile Red dye.
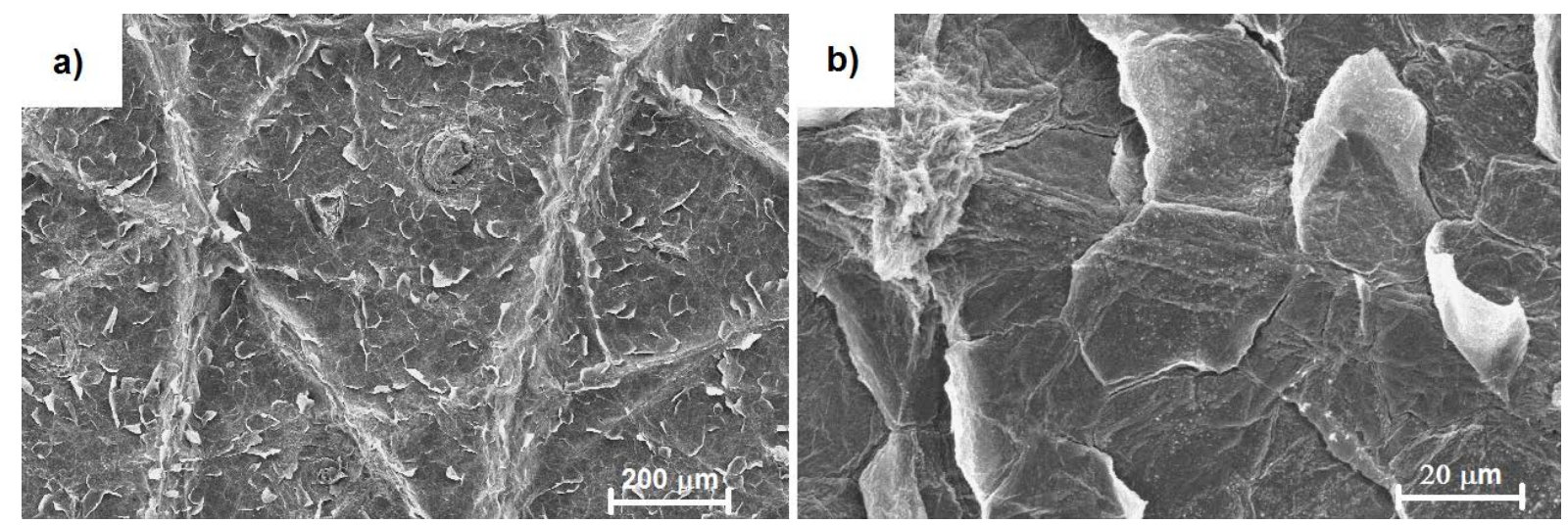

Figure 8. SEM picture of surface structure of lipid-stripping samples, (a) $100 \times$, (b) $1000 \times$ magnification; type of signal: secondary electron contrast. 
diation emitted by the used plasma discharges. The sample thickness is determined to amount to approximately $3 \mu \mathrm{m}$ where the surface structure is not affected by the stripping process as ascertained by SEM studies. A lipid content on the sample surface of approximately $30 \%$ is measured which was in a good agreement with stratum corneum. Lipid stripping thus turns out to be a suitable method for the cost-efficient and risk-free preparation of skin models for plasma medical studies and investigations.

\section{Acknowledgements}

This work was supported by the European Regional Development Funds (EFRE) and the Workgroup Innovative Projects of Lower Saxony (AGiP) in the frame of the Lower Saxony Innovation Network for Plasma Technology (NIP), project funding reference number W2-80029388. The authors would like to thank for the assistance provided in part by Anette Bennemann, Robert Koslowski and Prof. Michael Leck.

\section{References}

[1] Woedtke, T., Reuter, S., Masur, K. and Weltmann, K.-D. (2013) Plasmas for Medicine. Physics Reports, 530, $291-320$. http://dx.doi.org/10.1016/j.physrep.2013.05.005

[2] Weltmann, K.-D., Kindel, E., Brandenburg, R., Meyer, C., Bussiahn, R., Wilke, C. and Woedtke, T. (2009) Atmospheric Pressure Plasma Jet for Medical Therapy: Plasma Parameters and Risk Estimation. Contributions to Plasma Physics, 49, 631-640. http://dx.doi.org/10.1002/ctpp.200910067

[3] Kong, M., Kroesen, G., Morfill, G., Nosenko, T., Shimizu, T., Dijk, J. and Zimmermann, J. (2009) Plasma Medicine: an Introductory Review. New Journal of Physics, 11, Article ID: 115012. http://dx.doi.org/10.1088/1367-2630/11/11/115012

[4] Ehlbeck, J., Schnabel, U., Polak, M., Winter, J., Woedtke, T., Brandenburg, R., Hagen, T. and Weltmann, K.-D. (2011) Low Temperature Atmospheric Pressure Plasma Sources for Microbial Decontamination. Journal of Physics D: Applied Physics, 44, Article ID: 013002. http://dx.doi.org/10.1088/0022-3727/44/1/013002

[5] Tümmel, S., Mertens, N., Wang, J. and Viöl, W. (2007) Low Temperature Plasma Treatment of Living Human Cells. Plasma Processes and Polymers, 4, 465-469. http://dx.doi.org/10.1002/ppap.200731208

[6] Awakowicz, P., Bibinov, N., Born, M., Busse, B., Gesche, R., Helmke, A., Kaemling, A., Kolb-Bachofen, V., Kovacs, R., Kuehn, S., Liebmann, J., Mertens, N., Niemann, U., Oplaender, C., Porteanu, H.-E., Scherer, J., Suschek, C., Vioel, W. and Wandke, D. (2009) Biological Stimulation of the Human Skin Applying Health Promoting Light and Plasma Sources. Contributions to Plasma Physics, 49, 641-647. http://dx.doi.org/10.1002/ctpp.200910068

[7] Kuchenbecker, M., Bibinov, N., Kaemling, A., Wandke, D., Awakowicz, P. and Viöl, W. (2009) Characterization of DBD Plasma Source for Biomedical Applications. Journal of Physics D: Applied Physics, 42, Article ID: 045212. http://dx.doi.org/10.1088/0022-3727/42/4/045212

[8] Fridman, G., Peddinghaus, M., Ayan, H., Fridman, A., Balasubramanian, M., Gutsol, A., Brook, A. and Friedman, G. (2006) Blood Coagulation and Living Tissue Sterilization by Floating-Electrode Dielectric Barrier Discharge in Air. Plasma Chemistry and Plasma Processing, 26, 425-442. http://dx.doi.org/10.1007/s11090-006-9024-4

[9] Helmke, A., Grünig, P., Fritz, U-M., Wandke, D., Emmert, S., Petersen, K. and Viöl, W. (2012) Low-Temperature Plasma-A Prospective Microbicidal Tool. Recent Patents on Anti-Infective Drug Discovery, 7, 223-230. http://dx.doi.org/10.2174/157489112803521995

[10] Helmke, A., Hoffmeister, D., Berge, F., Emmert, S., Laspe, P., Mertens, N., Viöl, W. and Weltmann, K.-D. (2011) Physical and Microbiological Characterisation of Staphylococcus Epidermidis Inactivation by Dielectric Barrier Discharge Plasma. Plasma Processes and Polymers, 8, 278-286. http://dx.doi.org/10.1002/ppap.201000168

[11] Claiborne, D., McCombs, G., Lemaster, M., Akman, M. and Laroussi, M. (2014) Low-Temperature Atmospheric Pressure Plasma Enhanced Tooth Whitening: The Next-Generation Technology. International Journal of Dental Hygiene, 12, 108-114. http://dx.doi.org/10.1111/idh.12031

[12] Kalghatgi, S., Fridman, G., Cooper, M., Nagaraj, G., Peddinghaus, M., Balasubramanian, M., Vasilets, V., Gutsol, A., Fridman, A. and Friedman, G. (2007) Mechanism of Blood Coagulation by Nonthermal Atmospheric Pressure Dielectric Barrier Discharge Plasma. IEEE Transactions on Plasma Science, 35, 1559-1566. http://dx.doi.org/10.1109/TPS.2007.905953

[13] Jung, J., Yang, Y., Lee, D., Fridman, G., Fridman, A. and Cho, Y. (2011) Effect of Dielectric Barrier Discharge Treatment of Blood Plasma to Improve Rheological Properties of Blood. Plasma Chemistry and Plasma Processing, 32, 165-176. http://dx.doi.org/10.1007/s11090-011-9336-x

[14] Fridman, G., Shereshevsky, A., Jost, M., Brooks, A., Fridman, A., Gutsol, A., Vasilets, V. and Friedman, G. (2007) 
Floating Electrode Dielectric Barrier Discharge Plasma in Air Promoting Apoptotic Behavior in Melanoma Skin Cancer Cell Lines. Plasma Chemistry and Plasma Processing, 27, 163-176. http://dx.doi.org/10.1007/s11090-007-9048-4

[15] Barekzi, N. and Laroussi, M. (2012) Dose-Dependent Killing of Leukemia Cells by Low-Temperature Plasma. Journal of Physics D: Applied Physics, 45, Article ID: 422002.

[16] Helmke, A., Hoffmeister, D., Mertens, N., Emmert, S., Schütte, J. and Viöl, W. (2009) The Acidification of Lipid Film Surfaces by Non-Thermal DBD at Atmospheric Pressure in Air. New Journal of Physics, 11, Article ID: 115025.

[17] Marschewski, M., Hirschberg, J., Omairi, T., Höfft, O., Viöl, W., Emmert, S. and Maus-Friedrichs, W. (2012) Electron Spectroscopic Analysis of the Human Lipid Skin Barrier: Cold Plasma-Induced Changes in Lipid Composition. Experimental Dermatology, 21, 921-925. http://dx.doi.org/10.1111/exd.12043

[18] Lademann, J., Richter, H., Alborova, A., Humme, D. and Patzelt, A. (2009) Risk Assessment of the Application of a Plasma Jet in Dermatology. Journal of Biomedical Optics, 14, Article ID: 054025. http://dx.doi.org/10.1117/1.3247156

[19] Robert, E., Vandamme, M., Brullé, L., Lerondel, S., Le Pape, A., Sarron, V., Riès, D., Darny, T., Dozias, S., Collet, G. Kieda, C. and Pouvesle, J.M. (2013) Perspectives of Endoscopic Plasma Applications. Clinical Plasma Medicine, 1, 816. http://dx.doi.org/10.1016/j.cpme.2013.10.002

[20] Jungersted, J., Hellgren, L., Drachmann, T., Jemec, G. and Agner, T. (2010) Validation of Cyanoacrylate Method for Collection of Stratum Corneum in Human Skin for Lipid Analysis. Skin Pharmacology and Physiology, 23, 62-67.

[21] Hirschberg, J., Omairi, T., Mertens, N., Helmke, A., Emmert, S. and Viöl, W. (2013) Influence of Excitation Pulse Duration of Dielectric Barrier Discharges on Biomedical Applications. Journal of Physics D: Applied Physics, 46, Article ID: 165201.

[22] Ayan, H., Fridman, G., Gutsol, A., Vasilets, V., Fridman, A. and Friedman, G. (2008) Nanosecond-Pulsed Uniform Dielectric-Barrier Discharge. IEEE Transactions on Plasma Science, 36, 504-508. http://dx.doi.org/10.1109/TPS.2008.917947

[23] Ayan, H., Staack, D., Fridman, G., Gutsol, A., Mukhin, Y., Starikovskii, A., Fridman, A. and Friedman, G. (2009) Application of Nanosecond-Pulsed Dielectric Barrier Discharge for Biomedical Treatment of Topographically Non-Uniform Surfaces. Journal of Physics D: Applied Physics, 42, Article ID: 125202. http://dx.doi.org/10.1088/0022-3727/42/12/125202

[24] Merle, C., Laugel, C. and Baillet-Guffroy, A. (2010) Effect of UVA or UVB Irradiation on Cutaneous Lipids in Films or in Solution. Photochemistry and Photobiology, 86, 553-562. http://dx.doi.org/10.1111/j.1751-1097.2009.00690.x

[25] Tiede, R., Hirschberg, J., Daeschlein, G., von Woedtke, T., Vioel, W. and Emmert, S. (2014) Plasma Applications: A Dermatological View. Contributions to Plasma Physics, 54, 118-130. http://dx.doi.org/10.1002/ctpp.201310061

[26] Jabs, H-U. (2013) Stratum Corneum-From Corneobiochemistry to Corneotherapy. Ästhetische Dermatologie, 1, 1419.

[27] Stuecker, M., Struk, A., Altmeyer, P., Herde, M., Baumgaertl, H. and Luebbers, D.W. (2002) The Cutaneous Uptake of Atmospheric Oxygen Supply of Human Dermis and Epidermis. Journal of Physiology, 538, 985-994. http://dx.doi.org/10.1113/jphysiol.2001.013067

[28] Mertens, N. (2009) Low Temperature Plasma Treatment of Human Tissue. Proceedings of the 2nd International Conference on Plasma Medicine, San Antonio, 16-20 March 2009.

[29] Nielsen, K., Zhao, L., Stamnes, J., Stamnes, K. and Moan, J. (2008) The Optics of Human Skin: Aspects Important for Human Health. Norwegian Academy of Science and Letters, Oslo, 34-46. 
Scientific Research Publishing (SCIRP) is one of the largest Open Access journal publishers. It is currently publishing more than 200 open access, online, peer-reviewed journals covering a wide range of academic disciplines. SCIRP serves the worldwide academic communities and contributes to the progress and application of science with its publication.

Other selected journals from SCIRP are listed as below. Submit your manuscript to us via either submit@scirp.org or Online Submission Portal.
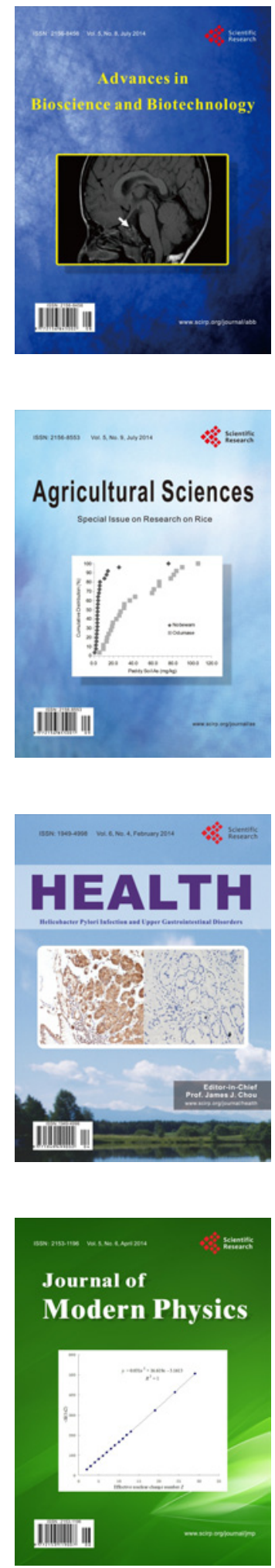
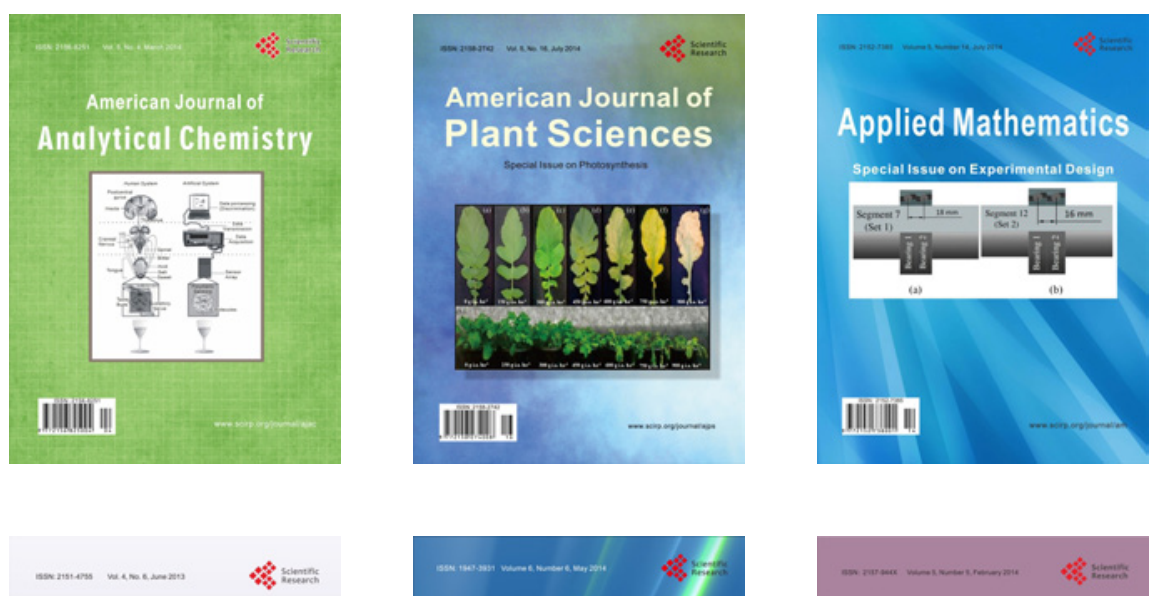

Creative Education
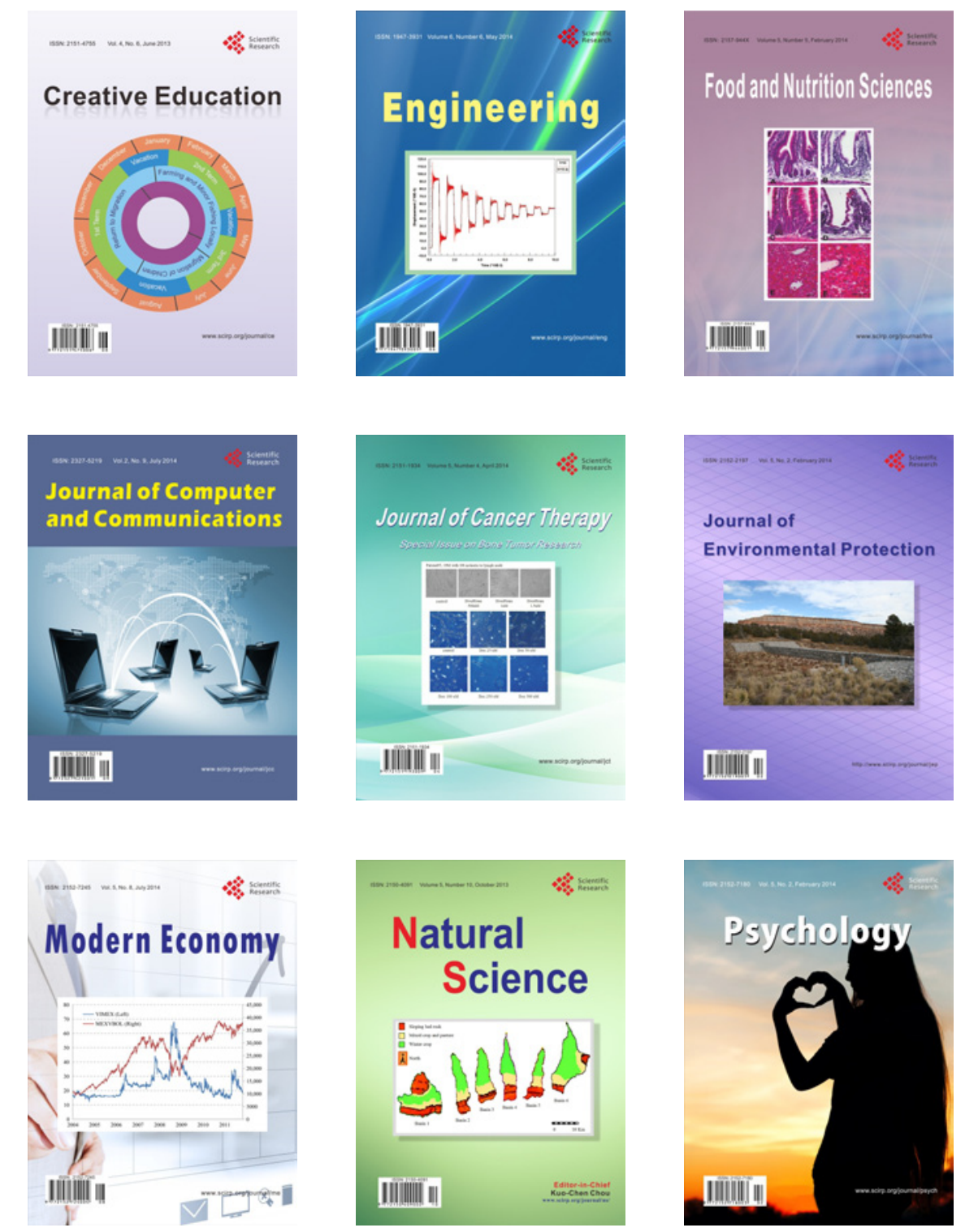